\title{
Role of exosomal miR-21 in the tumor microenvironment and osteosarcoma tumorigenesis and progression (Review)
}

\author{
SHOUFENG WANG ${ }^{1,2}$, FANG MA ${ }^{3}$, YI FENG $^{4}$, TANG LIU $^{1}$ and SHASHA HE ${ }^{3}$ \\ ${ }^{1}$ Department of Orthopedics, The Second Xiangya Hospital, Central South University, Changsha, Hunan 410000; \\ ${ }^{2}$ Department of Orthopedics, First Affiliated Hospital of Jiamusi University, Jiamusi, Heilongjiang 154003; \\ ${ }^{3}$ Department of Oncology, The Second Xiangya Hospital, Central South University, Changsha, Hunan 410000, P.R. China; \\ ${ }^{4}$ Ovarian Cancer Research, Perelman School of Medicine, University of Pennsylvania, Philadephia, PA 19104, USA
}

Received July 28, 2019; Accepted February 7, 2020

DOI: $10.3892 /$ ijo.2020.4992

\begin{abstract}
Osteosarcoma is the most common bone tumor affecting both adolescents and children. Early detection is critical for the effective treatment of the disease. Derived from cancer cells, miR-21 contained within exosomes in the tumor microenvironment may act on both cancer cells and the surrounding tumor microenvironment (TME), including immune cells, endothelial cells and fibroblasts. In human serum and plasm, the level of exosomal miR-21 between osteosarcoma patients and healthy controls differs, supporting the role of miR-21 as a biomarker for osteosarcoma. The involvement of a number of miR-21 target genes in tumor progression suggests that miR-21 may significantly affect the plasticity of cancer cells, leading to tumor progression, metastasis, angiogenesis and immune escape in osteosarcoma. Understanding the biogenesis and functions of exosomal miR-21 is of great value for the diagnosis and therapy of
\end{abstract}

Correspondence to: Dr Tang Liu, Department of Orthopedics, The Second Xiangya Hospital, Central South University, 139 Renmin Middle Road, Changsha, Hunan 410000, P.R. China

E-mail: liutang1204@csu.edu.cn

Dr Shasha He, Department of Oncology, The Second Xiangya Hospital, Central South University, 139 Renmin Middle Road, Changsha, Hunan 410000, P.R. China

E-mail: heshasha611@csu.edu.cn

Abbreviations: TME, tumor microenvironment; MVEs, multivesicular endosomes; 3' UTR, 3' untranslated region; PTEN, phosphatase and tensin homolog; PI3K/AKT, phosphoinositide 3-kinase/RAC- $\alpha$ serine/threonine-protein kinase; EMT, epithelialto-mesenchymal transition; VEGF, vascular endothelial growth factor; CAFs, cancer-associated fibroblasts; FAP, fibroblast-activated protein; $\alpha$-SMA, $\alpha$-smooth muscle actin; SDF-1, stromal-derived factor 1; TLR-8, Toll like receptor-8; MDSCs, myeloid-derived suppressor cells; ESCRT, endosomal sorting complex required for transport; RISC, RNA-induced silencing complex; TSAP6, tumor suppressor-activated pathway 6; NF1A, nuclear factor 1 A-type

Key words: miR-21, exosomes, tumor microenvironment, osteosarcoma, tumorigenesis, progression cancer, including osteosarcoma. The present review discusses the role of miR-21 in the tumor microenvironment, and in the development and progression of osteosarcoma, with an aim to summarize the functions of this miRNA in cancer.
Contents
1. Osteosarcoma
2. Exosomes
3. Exosomal miRNAs and cancer
4. Exosomal miR-21 and osteosarcoma
5. Exosomal miR-21 and the tumor microenvironment
6. Perspectives
7. Conclusions

\section{Osteosarcoma}

Osteosarcoma is the most common human primary malignant bone tumor affecting children and young adults (1), and is usually located in the distal femur, the proximal tibia, or the proximal humerus (2). The tumor is evolved from mesenchymal cells and is characterized by spindle cells and aberrant osteoid formation pathologically (3). The survival of patients with localized disease is increased with aggressive, multi-agent, neo-adjuvant chemotherapy and limb-salvage surgery. However, despite aggressive therapies, the long-term survival rate of patients with metastatic or recurrent disease however is $<20 \%(2,4,5)$. Although several genes have been reported to be involved in osteosarcoma tumorigenesis and therapeutic resistance (6-11), the precise molecular mechanisms involved in these processes remain unclear. The identification of clinically relevant diagnostic and prognostic biomarkers, such as circulating or cellular/tissue biomarkers, is, therefore, urgently required.

\section{Exosomes}

Exosomes are lipid bilayer membrane bound, nano-sized extracellular vesicles that are 40-100 $\mathrm{nm}$ in diameter (12-14). The exosomes are formed by pinching off of multivesicular 
endosomes (MVEs) on the membrane in the form of small intraluminal vesicles within the MVE and packing with cytoplasmic contents, including proteins, mRNAs and microRNAs (miRNAs or miRs) $(15,16)$. The secretion of exosomes occurs when MVEs fuse with the plasma membrane, and thus release the contents in exosomes into the extracellular environment. According to the exosome content database, ExoCarta, 9,769 proteins, 1,116 lipids, 3,408 mRNAs and 2,838 miRNAs have been identified in exosomes of different cell types in multiple organisms $(17,18)$.

Exosomes were first described as vesicles released from reticulocyte MVEs for the removal of obsolete transferrin receptors $(19,20)$. However, in recent years, exosomes have been considered to be important mediators of cellular communication in both normal physiological processes, and in the development and progression of diseases, such as cancer. Exosomes have been identified in the majority of bodily fluids, including the serum, urine, amniotic fluid, saliva, breastmilk, cerebrospinal fluid and nasal secretions $(21,22)$. Importantly, cancer cells secrete a greater number of exosomes compared to healthy cells (23), indicating their potential for use as diagnostic biomarkers.

\section{Exosomal miRNAs and cancer}

miRNAs are a class of small non-coding endogenous RNAs (18-24 nucleotides in length). miRNAs can act as post-transcriptional gene regulators by pairing with complementary sequences in the $3^{\prime}$ untranslated region (3' UTR) of target mRNAs, leading to mRNA degradation or translational repression $(24,25)$. miRNAs regulate a variety of cellular processes associated with carcinogenesis, such as cell proliferation, cell cycle, apoptosis, angiogenesis, invasion and metastasis (26-31).

The expression of miRNAs is altered in a variety of cancer types and is associated with the disease stage in some cases. Some specific miRNAs may contribute to tumor growth, progression, metastasis and drug resistance (32-35). Among these, miR-21 is most notable, since it has been extensively studied in various types of cancer. The majority of miRNAs detectable in serum and saliva is concentrated within exosomes (23). The level of miRNAs is similar in both circulating exosomes from cancer patients and tumor cells $(22,36)$. In a number of studies, the high expression of circulating miR-21 has been used to differentiate cancer patients from healthy individuals and predict disease outcomes (37 and refs. therein), suggesting that circulating exosome miRNAs, such as miR-21 can be utilized as for liquid biopsy miRNA profiling.

\section{Exosomal miR-21 and osteosarcoma}

hsa-mir-21 or miR-21 is an abundantly expressed miRNA in different types of mammalian cells (38-40), indicating its importance among miRNAs. miR-21 regulates biological processes, such as osteoclastogenesis, osteoclast differentiation, etc. Thus, miR-21 plays an essential role in the development of diseases, such as cancer, cardiovascular diseases and inflammation (41-43) The hsa-miR-21 gene is located on chromosome 17q23.2. Pri-miR-21 (primary transcript containing miR-21) is located within the intronic region of the tmem 49 gene. Even though pri-miR-21 and tmem 49 genes overlap in the same direction of transcription, pri-miR-21 is transcribed by its own promoter and is terminated with its own poly(A) tail. The pri-miR-21 transcript is subsequently processed into mature miR-21 $(44,45)$.

The expression of miR-21 has been found to be increased in the majority of cancer types analyzed, rendering it an established oncogenic miRNA (44-54). Functional analyses in epithelial-, hepatocyte- and glial cell-derived cell lines support the regulatory role of miR-21 in cell growth, migration and invasion $(46,47,55-57)$. Moreover, miR-21 and its associated pathways play a critical role in the pathogenesis of osteosarcoma and act as a therapeutic target for this tumor type (58). miR-21 exhibits a significantly higher expression in osteosarcoma tissues compared to adjacent normal tissues (59-61). miRNA expression has been shown to be positively associated with Enneking clinical staging and lung metastasis (62). Moreover, serum miR-21 has been reported to be a biomarker for chemosensitivity and the prognosis of human osteosarcoma (63). Additionally, circulating miR-21 levels are higher in patients with osteosarcoma than in healthy individuals. Studies have demonstrated that the detection of plasma miR-21 together with miR-143 and miR-199a-3p in patients with osteosarcoma can discriminate between the presence or absence of this tumor $(62,64)$. The evaluation of tumor metastasis and histopathological subtype from tumors of patients with osteosarcoma has revealed a higher level of miR-21 in patients with metastatic compared to non-metastatic disease (62).

\section{Exosomal miR-21 and tumor microenvironment}

The tumor microenvironment (TME) differs from that of normal tissues. The TME is composed of cellular and extracellular components. The cellular components of the TME involve cancer-associated fibroblasts (CAFs), myofibroblasts, adipocytes, endothelial cells, epithelial cells and immune inflammatory cells, such as T lymphocytes, B lymphocytes, natural killer cells and natural killer T-cells, and tumor-associated macrophages (65). Cells in the TME are in constant autocrine and paracrine communication, which contributes to tumor development, progression, drug resistance and metastasis (66-70).

Exosomes provide a unique method of information transfer both locally and globally by releasing their contents into the target cell, e.g., miRNAs. By releasing exosomes, tumor cells reprogram their surroundings in the TME into a tumor-permissive or tumor-promoting environment (71-74). mir-21 present in osteosarcoma cell-derived exosomes may affect the TME $(75,76)$, mediating the crosstalk between cancer cells, endothelial cells, immune cells, and fibroblasts in the TME to promote osteosarcoma development by i) the stimulation of tumor angiogenesis; ii) the inhibition of the immune response by acting directly on effector cells; iii) interfering with the regulation of stromal cell activation; and iv) the promotion of cancer progression by preparing the metastatic niche (Fig. 1).

miR-21 promotes cancer progression and metastasis (crosstalk among cancer cells). Cancer is a highly heterogeneous disease. A single tumor is composed of groups of genetically clonal cells 


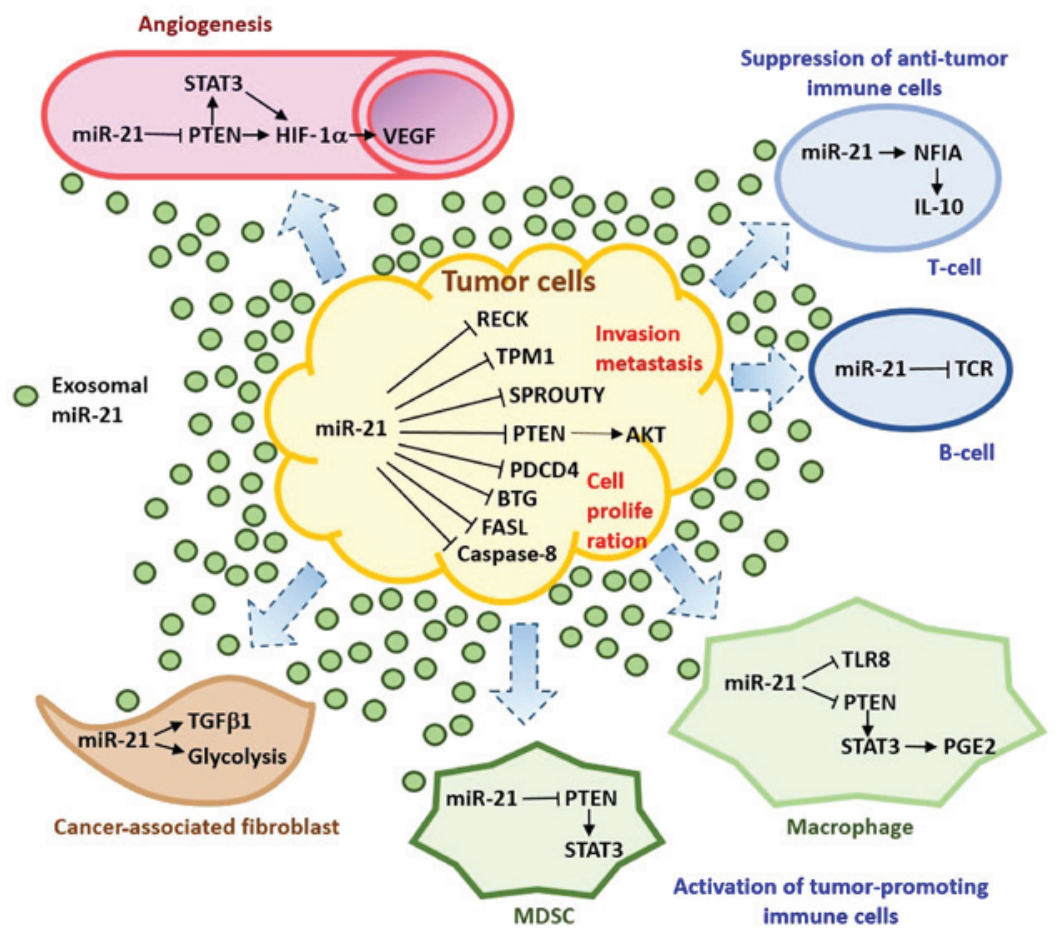

Figure 1. Exosomal miR-21 regulates the tumor microenvironment in osteosarcoma by targeting specific molecules in tumor cells, endothelial cells, cancer-associated fibroblasts and immune cells. The pathways depicted herein were deduced from studies focusing only on a specific cell type (75,76,83,85,86), and miR-21 is originated from other sources in addition to osteosarcoma. AKT, RAC-alpha serine/threonine-protein kinase; BTG, B-cell translocation gene; FASL, Fas ligand; NF1A, nuclear factor 1 A-type; PDCD4, programmed cell death 4; PTEN, phosphatase and tensin homolog; HIF-1 $\alpha$, hypoxia-inducible factor $1 \alpha$; RECK, reversion-inducing-cysteine-rich protein with Kazal motifs; STAT3, signal transducer and activator of transcription 3; TCR: T-cell receptor; PGE2, prostaglandin E2; TLR8; Toll-like receptor 8; TPM1, tropomyosin 1; VEGF, vascular endothelial growth factor.

that have different growth rates, metastatic potential, invasion potential and sensitivities to chemotherapy and radiotherapy. Individual malignant tumor cells can affect the invasion and migration of surrounding tumor cells by releasing exosomal miRNAs. In contrast to exosomes released from healthy cells, exosomes derived from patients with osteosarcoma have been shown to significantly increase the adhesion, migration and viability of MG63 human osteosarcoma cells (77). Synthetic miR-143 introduced into osteosarcoma cells is released via exosomes. The delivery of exosome-contained miR-143 significantly reduces the migration of osteosarcoma cells, suggesting that miRNAs in exosomes regulate the function of cancer cells (78).

miR-21 is suggested to function as an oncogene, since it promotes the growth and development of osteosarcoma and other cancer types. In MG-63 cells, the downregulation of miR-21 results in decreased proliferation and invasion. By contrast, the elevation of miR-21 by using a mimic increases cell proliferation and invasion (79). The phosphoinositide 3-kinase $(\mathrm{PI} 3 \mathrm{~K}) / \mathrm{RAC}-\alpha$ serine/threonine-protein kinase $(\mathrm{AKT}) / \mathrm{mammalian}$ target of rapamycin (mTOR) signaling pathway is one of the important pathways dysregulated in osteosarcoma (80-82). miR-21 may regulate the expression of the tumor suppressor phosphatase and tensin homolog (PTEN). The downregulation or deletion of PTEN activates the PI3K/AKT (phosphoinositide 3-kinase/RAC- $\alpha$ serine/threonine protein kinase) signaling pathway, leading to cancer development, invasion and metastasis $(83,84)$.

In addition to PTEN, miR-21 is suggested to target the TGF- $\beta 1$ signaling pathway to promote cell proliferation in osteosarcoma. miR-21 knockdown inhibits the proliferation of osteosarcoma and promotes the expression of PTEN and TGF- $\beta 1$ proteins in MG63 and U2OS human osteosarcoma cell lines (85). Moreover, it has been demonstrated that treatment with a TGF- $\beta 1$ inhibitor countered the inhibitory effects of miR-21 knockdown on osteosarcoma cell proliferation (86).

Caspase- 8 is a direct target of miR-21; miRNA negatively regulates the expression of caspase-8. The overexpression of miR-21 has been shown to enhance cell viability and survival, whereas it suppresses the apoptosis of the human osteosarcoma cell line, SAOS-2. In a subsequent study, miR-21 suppression was shown to increase caspase- 8 expression and decrease apoptosis (60).

miR-21 is a regulator of drug resistance in osteosarcoma. The suppression of miR-21 activity has been shown to enhance the resistance of U2OS cells to cisplatin, while the ectopic expression of miR-21 in MG-63 cells reduces the resistance. Elevated miR-21 levels suppress the expression of Sprouty2. On the other hand, the ectopic expression of Sprouty 2 has been shown to rescue the miR-21-mediated suppression of resistance to cisplatin, but not doxorubicin or methotrexate in osteosarcoma cells (87).

The process of metastasis is considered to be initiated in the majority, if not all, by an epithelial-to-mesenchymal transition (EMT) of the tumor cells. This allows them to migrate to and enter the vascular or lymphatic vessels, resulting in either local or distant metastasis $(88,89)$. miR-21 has been revealed to be an important miRNA associated with cancer invasion and metastasis. The study by Yan et al (90) demonstrated that miR-21 enhanced the invasion and migration of human 
breast cancer MCF7 and MDA-MB-231 cells, whereas cancer cell invasion was inhibited by the knockdown of miR-21. The mechanism of metastasis regulation by miR-21 is highly complex. miR-21 targets PDCD4, tropomyosin and PTEN that are known to modulate cancer cell invasion and metastasis (91-94). Moreover, miR-21 can inhibit PTEN expression and activate AKT signaling, inducing EMT, and promoting the invasion and migration of cancer cells (95-97). Furthermore, miR-21 can trigger the interleukin (IL)-6/signal transducer and activator of transcription (STAT)3/nuclear factor (NF)- $\kappa \mathrm{B}$-mediated signaling loop for the maintenance of EMT in cancer cells (98).

miR-21 induces tumor angiogenesis (crosstalk between tumor cells and endothelial cells). Tumor angiogenesis refers to the ability of tumor cells to recruit their own vasculature, which is critical for cancer progression. Several studies have demonstrated that exosome-encapsulated miRNAs secreted from tumor cells are able to induce angiogenesis in different cancertypes(99-102).ExosomalmiR-21 released by transformed lung cancer cells has been shown to induce vascular endothelial growth factor (VEGF) production and angiogenesis in nearby normal bronchial cells in a STAT3-dependent manner (99). In another study, the overexpression of miR-21 in the human prostate cancer cell line, DU145, was shown to increase the expression of Hypoxia-inducible factor (HIF)-1 $\alpha$ and VEGF, and induce tumor angiogenesis. The miR-21-mediated activation of the AKT and extracellular signal-regulated kinase (ERK)1/2 signaling pathways enhances HIF-1 $\alpha$ and VEGF expression (103).

miR-21 activates cancer-associated fibroblasts (CAFs; crosstalk between tumor cells and fibroblasts). CAFs become 'activated' during the neoplastic process. CAFs are capable of accelerating the growth and promoting the invasion of tumor cells (104-109). Cancer exosomes trigger the transformation of fibroblasts through the transforming growth factor (TGF) $\beta /$ Smad pathway and elicit unique effects from soluble TGF $\beta$. The depletion of miR-21 blocks TGF- $\beta 1$-induced CAF formation, whereas the overexpression of miR-21 promotes $\mathrm{CAF}$ induction, independent of TGF- $\beta 1$. These findings clearly demonstrate that miR-21 is a critical regulator of TGF- $\beta 1$ signaling induction of CAF formation (110). The conditioned medium from human lung cancer A549 cells has been shown to increase miR-21 expression and thus, through the TGF- $\beta$ pathway, induce migration, CAF-like morphology and CAF markers [periostin, $\alpha$-smooth muscle actin ( $\alpha$-SMA) and podoplanin] in human lung fibroblast MRC-5 and IMR-90 cells (111).

Exosomes from the multiple myeloma cell line, OPM2, have been showon to contain high levels of miR-21. The Co-culture of OPM2 exosomes with CAFs has also been shown to significantly increase the proliferation of and induce the CAF transformation of mesenchymal stem cells, demonstrated by the increased expression levels of fibroblast-activated protein (FAP), $\alpha$-SMA and stromal-derived factor 1 (SDF-1), and the secretion of IL-6 (112). In another study, miR-21 was demonstrated to induce the metabolic alteration of CAFs and to affect the development of the human pancreatic cancer cell line, BxPC-3. Compared to normal fibroblasts, CAFs exhibited an increased miR-21 expression, glucose uptake and lactic acid production. Treatment with a miR-21 inhibitor reduced glycolysis in CAFs. The co-culture of BxPC-3 cells with CAFs treated with the miR-21 inhibitor reduced oxidative phosphorylation and the invasion of BxPC-3 cells (113).

Exosomal miR-21 suppresses the immune system (crosstalk between tumor cells and immune cells). Exosomes secreted by tumor cells are able to inhibit the immune system by acting directly on effector cells or indirectly through their regulation (114-120). Tumor cells secrete miR-21 together with miR-29a to communicate with macrophages, eliciting a pro-inflammatory pro-metastatic response. miR-21 is a paracrine agonist of Toll-like receptor-8 (TLR-8). The activation of TLR-8 in immune cells triggers a pro-inflammatory response, that may lead to tumor growth and metastasis (121). miR-21 induces tumor-associated macrophage reprogramming through STAT3, and thereby facilitates growth, intravasation and the spread of tumor cells $(122,123)$.

Myeloid-derived suppressor cells (MDSCs) are the major myeloid cells responsible for the immune evasion of cancer. They are composed of a heterogeneous population of immature myeloid cell progenitors, macrophage precursors, granulocytes and dendritic cells. MDSCs can promote tumor growth by the promotion of angiogenesis or the suppression of innate and adaptive immune responses. miR-21 has been shown to be upregulated in bone marrow-derived and splenic MDSCs, and increases MDSC survival and proliferation by targeting PTEN and thus, STAT3 activation $(112,124)$.

miR-21 expression is higher in effector and memory $\mathrm{CD}^{+}$ T-cells than in naïve $\mathrm{CD}^{+} \mathrm{T}$-cells. Memory $\mathrm{CD} 8^{+} \mathrm{T}$-cells are emerging as a key player in tumor immunosurveillance (125), and recent evidence suggests that they can control tumor growth. miR-21 negatively regulates TCR signal transduction to modulate the sensitivity of memory T-cells $(118,119)$. Moreover, miR-21 may be involved in tumor-mediated immunosuppression $(120,126)$. miR-21 from C666-1 nasopharyngeal cancer cells has been shown to activate nuclear factor $1 \mathrm{~A}$-type (NF1-A) and induce IL-10 in B cells, which inhibits cytotoxic $\mathrm{CD}^{+}$T-cells (127).

\section{Perspectives}

Biogenesis of exosomal miR-21: Loading, release, and uptake. The majority of serum miRNAs is concentrated in exosomes. The loading of miRNAs into exosomes is dependent mainly on the surface molecules of exosome membranes, the endosomal sorting complex required for transport (ESCRT), and the specific binding motifs of the miRNAs themselves. A previous study demonstrated that miRNAs in exosomes are released through a ceramide-dependent secretory mechanism (128). Notably, exosomes secreted by cancer cells contain miRNAs associated with the miRNA-processing machinery RNA-induced silencing complex (RISC), and therefore, have the ability to process precursor miRNAs into mature miRNAs in a cell-independent manner, resulting in efficient and rapid reprogramming of transcriptome of the target cells (129).

Certain miRNAs are secreted selectively into exosomes. For example, the let-7 miRNA family in certain metastatic 
gastric cancer cell lines is secreted selectively to extracellular environment via exosomes (130). Breast cancer cell lines release the majority of miR-451 and miR-1246 selectively via exosomes, whereas both miRNAs are retained inside the non-malignant mammary epithelial cells and normal fibroblasts (131). Additionally, the TME may influence exosome release and uptake. The acidic microenvironment of tumors increases the rate of exosomal release and uptake by cancer cells (132). Furthermore, the aberrant exosome biogenesis and secretion in cancer cells, as compared with normal cells, may cause the differences in receptor recycling/degradation, plasma membrane remodeling, and the ability of endosomes to function as a signaling entity (133). In a number of types of cancer, aberrant p53 activity may result in the overexpression of the tumor suppressor-activated pathway 6 (TSAP6), through which it increases exosome production $(134,135)$. Furthermore, heparanase, an enzyme upregulated in numerous cancer cell lines, has been shown to regulate exosome secretion in cancer cells (136).

The level of exosomal miR-21 in serum is higher in patients with osteosarcoma than in healthy individuals, which is also reflected by the high levels of miR-21 found in tumor tissue (61-64). The molecular mechanisms of exosome sorting and release have been studied extensively recently. However, the differences in miRNA content between cancer- and healthy cell-derived exosomes, the differences in exosome biogenesis between cancer and healthy cells, and the reasons why cancer cells release more exosomes with distinct content, such as miR-21, remain unclear. Additionally, whether the release of miR-21 in exosomes occurs through a distinct secretary pathway remains to be elucidated. Further investigation into the distinct exosome cargo loading mechanisms for miR-21 and other miRNAs in osteosarcoma and other cancers may aid in the identification of specific therapeutic targets related to exosome biogenesis. Further research may facilitate the use of exosomes as delivery vehicles for drugs, antigens, etc., for cancer treatment in the future.

Exosomal miR-21 as a cancer biomarker. Exosomal miR-21 is detected in human serum and plasma. Differences in miR-21 expression have been found in serum or plasma from patients with osteosarcoma and in healthy controls, supporting the role of miR-21 as a biomarker for osteosarcoma (61-64). The advantages of using exosomal miR-21 as a non-invasive biomarker are that miRNAs in blood are persistent and are highly stable against destruction by ribonucleases $(137,138)$. The current methods used for exosome isolation include ultracentrifugation, size exclusion or precipitating with reagents (139). Ultracentrifugation is the commonly used method for exosome isolation. However, it is a lengthy process, which requires a large volume of samples and costly reagents and equipment. Thus, the method is impractical for clinical diagnosis. The size exclusion method uses columns to separate extracellular vesicles based on size and requires only a small amount of samples. However, the exosomes collected have heterogeneous sizes, curtailing the use for cancer diagnosis. The precipitation of exosomes with reagents not only pulls down miRNAs, but also protein aggregates that complicate the analysis for disease-specific markers.
In order to implement miR-21 as a biomarker for osteosarcoma, along with more effective methods for the isolation of cancer exosomes and exosomal miR-21, additional clinical trials are required to validate its use in the diagnosis of osteosarcoma and other types of cancer. Most importantly, miR-21 needs to be profiled together with other miRNAs or biomarkers specific to osteosarcoma to improve the reliability and specificity of miR-21 as a biomarker.

\section{Conclusions}

Exosomal miR-21 is detected in human serum and plasma. miR-21 expression in serum or plasma from patients with osteosarcoma differs from that in healthy controls, supporting the use of miR-21 as a biomarker for osteosarcoma. Exosomal miR-21 promotes cancer progression and development by mediating the crosstalk among cells in the TME. Larger-scale studies are warranted to further validate the sensitivity, specificity and applicability of circulating miR-21 as a biomarker for osteosarcoma in the future. Furthermore, extensive efforts need to be made to identify the specific cargo-loading mechanisms for exosomal miR-21. These studies will be critical for targeting miR-21 in cancer therapy to improve early-stage exosome- and miRNA-based therapeutics.

\section{Acknowledgements}

Not applicable.

\section{Funding}

This study was supported by the National Natural Science Foundation of China (grant nos. 81672176, 81871783 and 81702582).

\section{Availability of data and materials}

Not applicable.

\section{Authors' contributions}

SW and TL wrote the manuscript. SW performed the literature search for this review article. FM and YF revised and corrected the manuscript. FM and YF assisted in the literature search for this review article and also contributed to the conception and design of the study. FM contributed to processing of the figure. TL and SH conceived and designed the study. All authors read and approved the final manuscript.

\section{Ethics approval and consent to participate}

Not applicable.

\section{Patient consent for publication}

Not applicable.

\section{Competing interests}

The authors confirm they have competing interests. 


\section{References}

1. Meyers PA and Gorlick R: Osteosarcoma. Pediatr Clin North Am 44: 973-989, 1997.

2. Ottaviani G and Jaffe N: The epidemiology of osteosarcoma. Cancer Treat Res 152: 3-13, 2009.

3. Gill J, Ahluwalia MK, Geller D and Gorlick R: New targets and approaches in osteosarcoma. Pharmacol Ther 137: 89-99, 2013.

4. Ostenfeld MS, Jeppesen DK, Laurberg JR, Boysen AT, Bramsen JB, Primdal-Bengtson B, Hendrix A, Lamy P, Dagnaes-Hansen F, Rasmussen $\mathrm{MH}$, et al: Cellular disposal of miR23b by RAB27-dependent exosome release is linked to acquisition of metastatic properties. Cancer Res 74: 5758-5771, 2014.

5. Chou AJ, Geller DS and Gorlick R: Therapy for osteosarcoma: Where do we go from here? Paediatr Drugs 10: 315-327, 2008.

6. Sadikovic B, Yoshimoto M, Chilton-MacNeill S, Thorner P, Squire JA and Zielenska M: Identification of interactive networks of gene expression associated with osteosarcoma oncogenesis by integrated molecular profiling. Hum Mol Genet 18: 1962-1975, 2009.

7. Li Z, Dou P, Liu T and He S: Application of Long Noncoding RNAs in Osteosarcoma: Biomarkers and Therapeutic Targets. Cell Physiol Biochem 42: 1407-1419, 2017.

8. Zhou J, Liu T and Wang W: Prognostic significance of matrix metalloproteinase 9 expression in osteosarcoma: A meta-analysis of 16 studies. Medicine (Baltimore) 97: e13051, 2018.

9. Liu T, Yan Z, Liu Y, Choy E, Hornicek FJ, Mankin H and Duan Z: CRISPR-Cas9-Mediated Silencing of CD44 in Human Highly Metastatic Osteosarcoma Cells. Cell Physiol Biochem 46 1218-1230, 2018

10. Deng L, Liu T, Zhang B, Wu H, Zhao J and Chen J: Forkhead box $\mathrm{C} 1$ is targeted by microRNA-133b and promotes cell proliferation and migration in osteosarcoma. Exp Ther Med 14: 2823-2830, 2017.

11. Liu T,LiZ,Zhang Q,De Amorim Bernstein K,Lozano-Calderon S, Choy E, Hornicek FJ and Duan Z: Targeting ABCB1 (MDR1) in multi-drug resistant osteosarcoma cells using the CRISPR-Cas9 system to reverse drug resistance. Oncotarget 7: 83502-83513, 2016.

12. Simons M and Raposo G: Exosomes - vesicular carriers for intercellular communication. Curr Opin Cell Biol 21: 575-581, 2009.

13. Raposo G, Nijman HW, Stoorvogel W, Liejendekker R, Harding CV, Melief CJ and Geuze HJ: B lymphocytes secrete antigen-presenting vesicles. J Exp Med 183: 1161-1172, 1996.

14. Lee TH, D'Asti E, Magnus N, Al-Nedawi K, Meehan B and Rak J: Microvesicles as mediators of intercellular communication in cancer--the emerging science of cellular 'debris'. Semin Immunopathol 33: 455-467, 2011.

15. Kahlert C, Melo SA, Protopopov A, Tang J, Seth S, Koch M, Zhang J, Weitz J, Chin L, Futreal A, et al: Identification of double-stranded genomic DNA spanning all chromosomes with mutated KRAS and p53 DNA in the serum exosomes of patients with pancreatic cancer. J Biol Chem 289: 3869-3875, 2014.

16. Villarroya-Beltri C, Baixauli F, Gutiérrez-Vázquez C, Sánchez-Madrid F and Mittelbrunn M: Sorting it out: Regulation of exosome loading. Semin Cancer Biol 28: 3-13, 2014.

17. Mathivanan S, Fahner CJ, Reid GE and Simpson RJ: ExoCarta 2012: Database of exosomal proteins, RNA and lipids. Nucleic Acids Res 40 (D1): D1241-D1244, 2012.

18. Mathivanan S and Simpson RJ: ExoCarta: A compendium of exosomal proteins and RNA. Proteomics 9: 4997-5000, 2009.

19. Pan BT, Teng K, Wu C, Adam M and Johnstone RM: Electron microscopic evidence for externalization of the transferrin receptor in vesicular form in sheep reticulocytes. J Cell Biol 101: 942-948, 1985.

20. Harding C, Heuser J and Stahl P: Receptor-mediated endocytosis of transferrin and recycling of the transferrin receptor in rat reticulocytes. J Cell Biol 97: 329-339, 1983.

21. Keller S, Rupp C, Stoeck A, Runz S, Fogel M, Lugert S, Hager HD, Abdel-Bakky MS, Gutwein P and Altevogt P: CD24 is a marker of exosomes secreted into urine and amniotic fluid. Kidney Int 72: 1095-1102, 2007.

22. Taylor DD and Gercel-Taylor C: MicroRNA signatures of tumor-derived exosomes as diagnostic biomarkers of ovarian cancer. Gynecol Oncol 110: 13-21, 2008.

23. Gallo A, Tandon M, Alevizos I and Illei GG: The majority of microRNAs detectable in serum and saliva is concentrated in exosomes. PLoS One 7: e30679, 2012.
24. Bartel DP: MicroRNAs: Genomics, biogenesis, mechanism, and function. Cell 116: 281-297, 2004.

25. Bartel DP and Chen CZ: Micromanagers of gene expression: The potentially widespread influence of metazoan microRNAs. Nat Rev Genet 5: 396-400, 2004.

26. Chen LT, Xu SD, Xu H, Zhang JF, Ning JF and Wang SF: MicroRNA-378 is associated with non-small cell lung cancer brain metastasis by promoting cell migration, invasion and tumor angiogenesis. Med Oncol 29: 1673-1680, 2012.

27. Ivanovska I, Ball AS, Diaz RL, Magnus JF, Kibukawa M, Schelter JM, Kobayashi SV, Lim L, Burchard J, Jackson AL, et al: MicroRNAs in the miR-106b family regulate p21/CDKN1A and promote cell cycle progression. Mol Cell Biol 28: 2167-2174, 2008.

28. Lu Y, Thomson JM, Wong HY, Hammond SM and Hogan BL: Transgenic over-expression of the microRNA miR-17-92 cluster promotes proliferation and inhibits differentiation of lung epithelial progenitor cells. Dev Biol 310: 442-453, 2007.

29. Takamizawa J, Konishi H, Yanagisawa K, Tomida S, Osada H, Endoh H, Harano T, Yatabe Y, Nagino M, Nimura Y, et al: Reduced expression of the let-7 microRNAs in human lung cancers in association with shortened postoperative survival. Cancer Res 64: 3753-3756, 2004.

30. Wang ZX, Bian HB, Wang JR, Cheng ZX, Wang KM and De W: Prognostic significance of serum miRNA-21 expression in human non-small cell lung cancer. J Surg Oncol 104: 847-851, 2011.

31. Wang X, Ling C, Bai Y and Zhao J: MicroRNA-206 is associated with invasion and metastasis of lung cancer. Anat Rec (Hoboken) 294: 88-92, 2011.

32. Ferracin M, Veronese A and Negrini M: Micromarkers: miRNAs in cancer diagnosis and prognosis. Expert Rev Mol Diagn 10: 297-308, 2010.

33. Nana-Sinkam P and Croce CM: MicroRNAs in diagnosis and prognosis in cancer: What does the future hold? Pharmacogenomics 11: 667-669, 2010.

34. Fan H, Lu S, Wang S and Zhang S: Identification of critical genes associated with human osteosarcoma metastasis based on integrated gene expression profiling. Mol Med Rep 20: 915-930, 2019.

35. Gulino R, Forte S, Parenti R, Memeo L and Gulisano M: MicroRNA and pediatric tumors: Future perspectives. Acta Histochem 117: 339-354, 2015.

36. Rabinowits G, Gerçel-Taylor C, Day JM, Taylor DD and Kloecker GH: Exosomal microRNA: A diagnostic marker for lung cancer. Clin Lung Cancer 10: 42-46, 2009.

37. Wang Y, Gao X, Wei F, Zhang X, Yu J, Zhao H, Sun Q, Yan F, Yan C, Li H, et al: Diagnostic and prognostic value of circulating miR-21 for cancer: A systematic review and meta-analysis. Gene 533: 389-397, 2014.

38. Lagos-Quintana M, Rauhut R, Lendeckel W and Tuschl T: Identification of novel genes coding for small expressed RNAs. Science 294: 853-858, 2001

39. Lagos-Quintana M, Rauhut R, Yalcin A, Meyer J, Lendeckel W and Tuschl T: Identification of tissue-specific microRNAs from mouse. Curr Biol 12: 735-739, 2002.

40. Landgraf P, Rusu M, Sheridan R, Sewer A, Iovino N, Aravin A, Pfeffer S, Rice A, Kamphorst AO, Landthaler M, et al: A mammalian microRNA expression atlas based on small RNA library sequencing. Cell 129: 1401-1414, 2007.

41. Kumarswamy R, Volkmann I and Thum T: Regulation and function of miRNA-21 in health and disease. RNA Biol 8: 706-713, 2011.

42. Hu CH, Sui BD, Du FY, Shuai Y, Zheng CX, Zhao P, Yu XR and Jin Y: miR-21 deficiency inhibits osteoclast function and prevents bone loss in mice. Sci Rep 7: 43191, 2017.

43. Li X, Guo L, Liu Y, Su Y, Xie Y, Du J, Zhou J, Ding G, Wang H, Bai Y, et al: MicroRNA-21 promotes osteogenesis of bone marrow mesenchymal stem cells via the Smad7-Smad1/5/8-Runx2 pathway. Biochem Biophys Res Commun 493: 928-933, 2017.

44. Krichevsky AM and Gabriely G: miR-21: A small multi-faceted RNA. J Cell Mol Med 13: 39-53, 2009.

45. Pan X, Wang ZX and Wang R: MicroRNA-21: A novel therapeutic target in human cancer. Cancer Biol Ther 10: 1224-1232, 2010.

46. Asangani IA, Rasheed SA, Nikolova DA, Leupold JH, Colburn NH, Post S and Allgayer H: MicroRNA-21 (miR-21) post-transcriptionally downregulates tumor suppressor Pdcd4 and stimulates invasion, intravasation and metastasis in colorectal cancer. Oncogene 27: 2128-2136, 2008. 
47. Frankel LB, Christoffersen NR, Jacobsen A, Lindow M, Krogh A and Lund AH: Programmed cell death 4 (PDCD4) is an important functional target of the microRNA miR-21 in breast cancer cells. J Biol Chem 283: 1026-1033, 2008.

48. Li T, Li D, Sha J, Sun P and Huang Y: MicroRNA-21 directly targets MARCKS and promotes apoptosis resistance and invasion in prostate cancer cells. Biochem Biophys Res Commun 383: 280-285, 2009.

49. Lu Z, Liu M, Stribinskis V, Klinge CM, Ramos KS, Colburn NH and Li Y: MicroRNA-21 promotes cell transformation by targeting the programmed cell death 4 gene. Oncogene 27: 4373-4379, 2008.

50. Zhu S, Si ML, Wu H and Mo YY: MicroRNA-21 targets the tumor suppressor gene tropomyosin 1 (TPM1). J Biol Chem 282: 14328-14336, 2007.

51. Zhu S, Wu H, Wu F, Nie D, Sheng S and Mo YY: MicroRNA-21 targets tumor suppressor genes in invasion and metastasis. Cell Res 18: 350-359, 2008.

52. Zheng J, Xue H, Wang T, Jiang Y, Liu B, Li J, Liu Y, Wang W, Zhang B and Sun M: miR-21 downregulates the tumor suppressor P12 CDK2AP1 and stimulates cell proliferation and invasion. J Cell Biochem 112: 872-880, 2011.

53. Xu J, Wu C, Che X, Wang L, Yu D, Zhang T, Huang L, Li H, Tan W, Wang C, et al: Circulating microRNAs, miR-21, miR-122, and miR-223, in patients with hepatocellular carcinoma or chronic hepatitis. Mol Carcinog 50: 136-142, 2011.

54. Schramedei K, Mörbt N, Pfeifer G, Läuter J, Rosolowski M, Tomm JM, von Bergen M, Horn F and Brocke-Heidrich $\mathrm{K}$ : MicroRNA-21 targets tumor suppressor genes ANP32A and SMARCA4. Oncogene 30: 2975-2985, 2011.

55. Gabriely G, Wurdinger T, Kesari S, Esau CC, Burchard J, Linsley PS and Krichevsky AM: MicroRNA 21 promotes glioma invasion by targeting matrix metalloproteinase regulators. Mol Cell Biol 28: 5369-5380, 2008

56. Meng F, Henson R, Wehbe-Janek H, Ghoshal K, Jacob ST and Patel T: MicroRNA-21 regulates expression of the PTEN tumor suppressor gene in human hepatocellular cancer. Gastroenterology 133: 647-658, 2007.

57. Si ML, Zhu S, Wu H, Lu Z, Wu F and Mo YY: miR-21-mediated tumor growth. Oncogene 26: 2799-2803, 2007

58. Sekar D, Mani P, Biruntha M, Sivagurunathan $\mathrm{P}$ and Karthigeyan M: Dissecting the functional role of microRNA 21 in osteosarcoma. Cancer Gene Ther 26: 179-182, 2019.

59. Hua Y, Jin Z, Zhou F, Zhang YQ and Zhuang Y: The expression significance of serum MiR-21 in patients with osteosarcoma and its relationship with chemosensitivity. Eur Rev Med Pharmacol Sci 21: 2989-2994, 2017.

60. Xu B, Xia H, Cao J, Wang Z, Yang Y and Lin Y: MicroRNA-21 Inhibits the Apoptosis of Osteosarcoma Cell Line SAOS-2 via Targeting Caspase 8. Oncol Res 25: 1161-1168, 2017.

61. Ren X, Shen Y,Zheng S, Liu J and Jiang X: miR-21 predicts poor prognosis in patients with osteosarcoma. Br J Biomed Sci 73: 158-162, 2016

62. Zhao H, Yan P, Wang J, Zhang Y, Zhang M, Wang Z, Fu Q and Liang W: Clinical significance of tumor miR-21, miR-221, miR-143, and miR-106a as biomarkers in patients with osteosarcoma. Int J Biol Markers 34: 184-193, 2019.

63. Yuan J, Chen L, Chen X, Sun W and Zhou X: Identification of serum microRNA-21 as a biomarker for chemosensitivity and prognosis in human osteosarcoma. J Int Med Res 40: 2090-2097, 2012

64. Ouyang L, Liu P, Yang S, Ye S, Xu W and Liu X: A three-plasma miRNA signature serves as novel biomarkers for osteosarcoma. Med Oncol 30: 340, 2013

65. Whiteside TL: The tumor microenvironment and its role in promoting tumor growth. Oncogene 27: 5904-5912, 2008.

66. Cretu A and Brooks PC: Impact of the non-cellular tumor microenvironment on metastasis: Potential therapeutic and imaging opportunities. J Cell Physiol 213: 391-402, 2007.

67. Hartmann S, Bhola NE and Grandis JR: HGF/Met Signaling in Head and Neck Cancer: Impact on the Tumor Microenvironment Clin Cancer Res 22: 4005-4013, 2016.

68. Gu F, Hu C, Tai Z, Yao C, Tian J, Zhang L, Xia Q, Gong C, Gao Y and Gao S: Tumour microenvironment-responsive lipoic acid nanoparticles for targeted delivery of docetaxel to lung cancer. Sci Rep 6: 36281, 2016

69. Friedl P and Alexander S: Cancer invasion and the microenvironment: Plasticity and reciprocity. Cell 147: 992-1009, 2011

70. Wu T, Hong Y, Jia L, Wu J, Xia J, Wang J, Hu Q and Cheng B: Modulation of IL-1 $\beta$ reprogrammes the tumor microenvironment to interrupt oral carcinogenesis. Sci Rep 6: 20208, 2016.
71. Maia J, Caja S, Strano Moraes MC, Couto N and Costa-Silva B: Exosome-Based Cell-Cell Communication in the Tumor Microenvironment. Front Cell Dev Biol 6: 18, 2018.

72. Hu C, Chen M, Jiang R, Guo Y, Wu M and Zhang X: Exosome-related tumor microenvironment. J Cancer 9: 3084-3092, 2018

73. Wang Z, Chen JQ, Liu JL and Tian L: Exosomes in tumor microenvironment: Novel transporters and biomarkers. J Transl Med 14: 297, 2016

74. Milane L, Singh A, Mattheolabakis G, Suresh M and Amiji MM: Exosome mediated communication within the tumor microenvironment. J Control Release 219: 278-294, 2015.

75. Raimondi L, De Luca A, Gallo A, Costa V, Russelli G, Cuscino N, Manno M, Raccosta S, Carina V, Bellavia D, et al: Osteosarcoma cell-derived exosomes affect tumor microenvironment by specific packaging of microRNAs. Carcinogenesis: Jul 10, 2019 (Epub ahead of print).

76. Jerez S, Araya H, Hevia D, Irarrázaval CE, Thaler R, van Wijnen AJ and Galindo M: Extracellular vesicles from osteosarcoma cell lines contain miRNAs associated with cell adhesion and apoptosis. Gene 710: 246-257, 2019.

77. Shen RK, Zhu X, Yi H, Wu CY, Chen F, Dai LQ and Lin JH: Proteomic identification of osteosarcoma-derived exosomes and their activation of pentose phosphate pathway. Int J Clin Exp Pathol 9: 4140-4148, 2016

78. Shimbo K, Miyaki S, Ishitobi H, Kato Y, Kubo T, Shimose S and Ochi M: Exosome-formed synthetic microRNA-143 is transferred to osteosarcoma cells and inhibits their migration. Biochem Biophys Res Commun 445: 381-387, 2014.

79. Lv C, Hao Y and Tu G: MicroRNA-21 promotes proliferation, invasion and suppresses apoptosis in human osteosarcoma line MG63 through PTEN/Akt pathway. Tumour Biol 37: 9333-9342, 2016.

80. Graziano AC, Cardile V, Avola R, Vicario N, Parenti C, Salvatorelli L, Magro G and Parenti R: Wilms' tumor gene 1 silencing inhibits proliferation of human osteosarcoma MG-63 cell line by cell cycle arrest and apoptosis activation. Oncotarget 8: 13917-13931, 2017.

81. Wang L, Tang B, Han H, Mao D, Chen J, Zeng Y and Xiong M: miR-155 Affects Osteosarcoma MG-63 Cell Autophagy Induced by Adriamycin Through Regulating PTEN-PI3K/AKT/mTOR Signaling Pathway. Cancer Biother Radiopharm 33: 32-38, 2018 .

82. Zhang J, Yu XH, Yan YG, Wang $\mathrm{C}$ and Wang WJ: PI3K/Akt signaling in osteosarcoma. Clin Chim Acta 444: 182-192, 2015.

83. Wu YR, Qi HJ, Deng DF, Luo YY and Yang SL: MicroRNA-21 promotes cell proliferation, migration, and resistance to apoptosis through PTEN/PI3K/AKT signaling pathway in esophageal cancer. Tumour Biol 37: 12061-12070, 2016.

84. Xue R, Lei S, Xia ZY, Wu Y, Meng Q, Zhan L, Su W, Liu H, Xu J, Liu Z, et al: Selective inhibition of PTEN preserves ischaemic post-conditioning cardioprotection in STZ-induced Type 1 diabetic rats: Role of the PI3K/Akt and JAK2/STAT3 pathways. Clin Sci (Lond) 130: 377-392, 2016.

85. Li C, Xu B, Miu X, Deng Z, Liao H and Hao L: Inhibition of miRNA-21 attenuates the proliferation and metastasis of human osteosarcoma by upregulating PTEN. Exp Ther Med 15: 1036-1040, 2018

86. Hu X, Li L, Lu Y, Yu X, Chen H, Yin Q and Zhang Y: miRNA-21 inhibition inhibits osteosarcoma cell proliferation by targeting PTEN and regulating the TGF- $\beta 1$ signaling pathway. Oncol Lett 16: 4337-4342, 2018.

87. Vanas V, Haigl B, Stockhammer V and Sutterlüty-Fall H MicroRNA-21 Increases Proliferation and Cisplatin Sensitivity of Osteosarcoma-Derived Cells. PLoS One 11: e0161023, 2016.

88. Heerboth S, Housman G, Leary M, Longacre M, Byler S, Lapinska K, Willbanks A and Sarkar S: EMT and tumor metastasis. Clin Transl Med 4: 6, 2015.

89. Karlsson MC, Gonzalez SF, Welin J and Fuxe J: Epithelial-mesenchymal transition in cancer metastasis through the lymphatic system. Mol Oncol 11: 781-791, 2017.

90. Yan LX, Wu QN, Zhang Y, Li YY, Liao DZ, Hou JH, Fu J, Zeng MS, Yun JP, Wu QL, et al: Knockdown of miR-21 in human breast cancer cell lines inhibits proliferation, in vitro migration and in vivo tumor growth. Breast Cancer Res 13: R2, 2011.

91. Zhao MY, Wang LM, Liu J, Huang X, Liu J and Zhang YF: MiR-21 Suppresses Anoikis through Targeting PDCD4 and PTEN in Human Esophageal Adenocarcinoma. Curr Med Sci 38: 245-251, 2018 
92.Liao J, Liu R, Shi YJ, Yin LH and Pu YP: Exosome-shuttling microRNA-21 promotes cell migration and invasion-targeting PDCD4 in esophageal cancer. Int J Oncol 48: 2567-2579, 2016.

93. Melnik BC: MiR-21: An environmental driver of malignant melanoma? J Transl Med 13: 202, 2015.

94.Jiang LH, Ge MH, Hou XX, Cao J, Hu SS, Lu XX, Han J, Wu YC, Liu X, Zhu X, et al: miR-21 regulates tumor progression through the miR-21-PDCD4-Stat3 pathway in human salivary adenoid cystic carcinoma. Lab Invest 95: 1398-1408, 2015.

95. Bera A, Das F, Ghosh-Choudhury N, Kasinath BS, Abboud HE and Choudhury GG: microRNA-21-induced dissociation of PDCD4 from rictor contributes to Akt-IKK $\beta$-mTORC1 axis to regulate renal cancer cell invasion. Exp Cell Res 328: 99-117, 2014.

96.Zhao M, Ang L, Huang J and Wang J: MicroRNAs regulate the epithelial-mesenchymal transition and influence breast cancer invasion and metastasis. Tumour Biol 39: 1010428317691682, 2017

97. Han M, Wang Y, Liu M, Bi X, Bao J, Zeng N, Zhu Z, Mo Z, Wu $\mathrm{C}$ and Chen X: MiR-21 regulates epithelial-mesenchymal transition phenotype and hypoxia-inducible factor-1 $\alpha$ expression in third-sphere forming breast cancer stem cell-like cells. Cancer Sci 103: 1058-1064, 2012.

98. De Mattos-Arruda L, Bottai G, Nuciforo PG, Di Tommaso L, Giovannetti E, Peg V, Losurdo A, Pérez-Garcia J, Masci G, Corsi F, et al: MicroRNA-21 links epithelial-to-mesenchymal transition and inflammatory signals to confer resistance to neoadjuvant trastuzumab and chemotherapy in HER2-positive breast cancer patients. Oncotarget 6: 37269-37280, 2015

99. Liu Y, Luo F, Wang B, Li H, Xu Y, Liu X, Shi L, Lu X, Xu W, Lu L, et al: STAT3-regulated exosomal miR-21 promotes angiogenesis and is involved in neoplastic processes of transformed human bronchial epithelial cells. Cancer Lett 370: 125-135, 2016.

100. Mao G, Liu Y, Fang X, Liu Y, Fang L, Lin L, Liu X and Wang N: Tumor-derived microRNA-494 promotes angiogenesis in non-small cell lung cancer. Angiogenesis 18: 373-382, 2015.

101.Umezu T, Tadokoro H, Azuma K, Yoshizawa S, Ohyashiki K and Ohyashiki JH: Exosomal miR-135b shed from hypoxic multiple myeloma cells enhances angiogenesis by targeting factor-inhibiting HIF-1. Blood 124: 3748-3757, 2014.

102.Lin XJ, Fang JH, Yang XJ, Zhang C, Yuan Y, Zheng L and Zhuang SM: Hepatocellular Carcinoma Cell-Secreted Exosomal MicroRNA-210 Promotes Angiogenesis In Vitro and In Vivo. Mol Ther Nucleic Acids 11: 243-252, 2018.

103. Liu LZ, Li C, Chen Q, Jing Y, Carpenter R, Jiang Y, Kung HF, Lai L and Jiang BH: MiR-21 induced angiogenesis through AKT and ERK activation and HIF-1 $\alpha$ expression. PLoS One 6 : e19139, 2011.

104. Brentnall TA: Arousal of cancer-associated stromal fibroblasts: Palladin-activated fibroblasts promote tumor invasion. Cell Adhes Migr 6: 488-494, 2012.

105. Orimo A, Gupta PB, Sgroi DC, Arenzana-Seisdedos F, Delaunay T, Naeem R, Carey VJ, Richardson AL and Weinberg RA: Stromal fibroblasts present in invasive human breast carcinomas promote tumor growth and angiogenesis through elevated SDF-1/CXCL12 secretion. Cell 121: 335-348, 2005.

106. Camps JL, Chang SM, Hsu TC, Freeman MR, Hong SJ, Zhau HE, von Eschenbach AC and Chung LW: Fibroblast-mediated acceleration of human epithelial tumor growth in vivo. Proc Natl Acad Sci USA 87: 75-79, 1990.

107. Gleave M, Hsieh JT, Gao CA, von Eschenbach AC and Chung LW: Acceleration of human prostate cancer growth in vivo by factors produced by prostate and bone fibroblasts. Cancer Res 51: 3753-3761, 1991.

108. Kanekura T, Chen X and Kanzaki T: Basigin (CD147) is expressed on melanoma cells and induces tumor cell invasion by stimulating production of matrix metalloproteinases by fibroblasts. Int J Cancer 99: 520-528, 2002.

109. Sameshima T, Nabeshima K, Toole BP, Yokogami K, Okada Y, Goya T and Wakisaka S: Glioma cell extracellular matrix metalloproteinase inducer (EMMPRIN) (CD147) stimulates production of membrane-type matrix metalloproteinases and activated gelatinase A in co-cultures with brain-derived fibroblasts. Cancer Lett 157: 177-184, 2000

110. Li Q, Zhang D, Wang Y, Sun P, Hou X, Larner J, Xiong W and Mi J: MiR-21/Smad 7 signaling determines TGF- $\beta 1$-induced CAF formation. Sci Rep 3: 2038, 2013
111. Kunita A, Morita S, Irisa TU, Goto A, Niki T, Takai D, Nakajima J and Fukayama M: MicroRNA-21 in cancer-associated fibroblasts supports lung adenocarcinoma progression. Sci Rep 8: 8838, 2018.

112. Cheng Q, Li X, Liu J, Ye Q, Chen Y, Tan S and Liu J: Multiple Myeloma-Derived Exosomes Regulate the Functions of Mesenchymal Stem Cells Partially via Modulating miR-21 and miR-146a. Stem Cells Int 2017: 9012152, 2017.

113. Mace TA, Collins AL, Wojcik SE, Croce CM, Lesinski GB and Bloomston M: Hypoxia induces the overexpression of microRNA-21 in pancreatic cancer cells. J Surg Res 184: $855-860,2013$

114. Muller L, Mitsuhashi M, Simms P, Gooding WE and Whiteside TL: Tumor-derived exosomes regulate expression of immune function-related genes in human T cell subsets. Sci Rep 6: 20254, 2016.

115. Greening DW, Gopal SK, Xu R, Simpson RJ and Chen W: Exosomes and their roles in immune regulation and cancer. Semin Cell Dev Biol 40: 72-81, 2015.

116. Kurywchak P, Tavormina J and Kalluri R: The emerging roles of exosomes in the modulation of immune responses in cancer. Genome Med 10: 23, 2018.

117. Robbins PD and Morelli AE: Regulation of immune responses by extracellular vesicles. Nat Rev Immunol 14: 195-208, 2014.

118. Wang L, He L, Zhang R, Liu X, Ren Y, Liu Z, Zhang X, Cheng W and Hua ZC: Regulation of T lymphocyte activation by microRNA-21. Mol Immunol 59: 163-171, 2014.

119. Carissimi C, Carucci N, Colombo T, Piconese S, Azzalin G, Cipolletta E, Citarella F, Barnaba V, Macino G and Fulci V: miR-21 is a negative modulator of T-cell activation. Biochimie 107 (Pt B): 319-326, 2014

120. Sheedy FJ: Turning 21: Induction of miR-21 as a Key Switch in the Inflammatory Response. Front Immunol 6: 19, 2015.

121. Fabbri M, Paone A, Calore F, Galli R, Gaudio E, Santhanam R, Lovat F, Fadda P, Mao C, Nuovo GJ, et al: MicroR NAs bind to Toll-like receptors to induce prometastatic inflammatory response. Proc Natl Acad Sci USA 109: E2110-E2116, 2012.

122. Wang Z, Brandt S, Medeiros A, Wang S, Wu H, Dent A and Serezani CH: MicroRNA 21 is a homeostatic regulator of macrophage polarization and prevents prostaglandin E2-mediated M2 generation. PLoS One 10: e0115855, 2015.

123. Curtale G: MiRNAs at the Crossroads between Innate Immunity and Cancer: Focus on Macrophages. Cells 7: E12, 2018.

124. Li L, Zhang J, Diao W, Wang D, Wei Y, Zhang CY and Zen K: MicroRNA-155 and MicroRNA-21 promote the expansion of functional myeloid-derived suppressor cells. J Immunol 192: 1034-1043, 2014.

125. Klebanoff CA, Gattinoni L and Restifo NP: CD8+ T-cell memory in tumor immunology and immunotherapy. Immunol Rev 211: 214-224, 2006.

126. Cereghetti DM and Lee PP: Tumor-Derived Exosomes Contain microRNAs with Immunological Function: Implications for a Novel Immunosuppression Mechanism. MicroRNA 2: 194-204, 2014.

127. Miao BP, Zhang RS, Li M, Fu YT, Zhao M, Liu ZG and Yang PC: Nasopharyngeal cancer-derived microRNA-21 promotes immune suppressive B cells. Cell Mol Immunol 12: 750-756, 2015.

128. Kosaka N, Iguchi H, Yoshioka Y, Takeshita F, Matsuki Y and Ochiya T: Secretory mechanisms and intercellular transfer of microRNAs in living cells. J Biol Chem 285: 17442-17452, 2010

129. Melo SA, Sugimoto H, O'Connell JT, Kato N, Villanueva A, Vidal A, Qiu L, Vitkin E, Perelman LT, Melo CA, et al: Cancer exosomes perform cell-independent microRNA biogenesis and promote tumorigenesis. Cancer Cell 26: 707-721, 2014.

130. Ohshima K, Inoue K, Fujiwara A, Hatakeyama K, Kanto K, Watanabe Y, Muramatsu K, Fukuda Y, Ogura S, Yamaguchi K, et al: Let-7 microRNA family is selectively secreted into the extracellular environment via exosomes in a metastatic gastric cancer cell line. PLoS One 5: e13247, 2010.

131. Pigati L, Yaddanapudi SC, Iyengar R, Kim DJ, Hearn SA, Danforth D, Hastings ML and Duelli DM: Selective release of microRNA species from normal and malignant mammary epithelial cells. PLoS One 5: e13515, 2010.

132. Boussadia Z, Lamberti J, Mattei F, Pizzi E, Puglisi R, Zanetti C, Pasquini L, Fratini F, Fantozzi L, Felicetti F, et al: Acidic microenvironment plays a key role in human melanoma progression through a sustained exosome mediated transfer of clinically relevant metastatic molecules. J Exp Clin Cancer Res 37: 245, 2018 . 
133. Hessvik NP and Llorente A: Current knowledge on exosome biogenesis and release. Cell Mol Life Sci 75: 193-208, 2018.

134.Lespagnol A, Duflaut D, Beekman C, Blanc L, Fiucci G, Marine JC, Vidal M, Amson $\mathrm{R}$ and Telerman A: Exosome secretion, including the DNA damage-induced p53-dependent secretory pathway, is severely compromised in TSAP6/Steap3-null mice. Cell Death Differ 15: 1723-1733, 2008.

135. Yu X, Harris SL and Levine AJ: The regulation of exosome secretion: A novel function of the p53 protein. Cancer Res 66: 4795-4801, 2006.

136. Thompson CA, Purushothaman A, Ramani VC, Vlodavsky I and Sanderson RD: Heparanase regulates secretion, composition, and function of tumor cell-derived exosomes. J Biol Chem 288: 10093-10099, 2013
137. Wang K, Zhang S, Marzolf B, Troisch P, Brightman A, Hu Z, Hood LE and Galas DJ: Circulating microRNAs, potential biomarkers for drug-induced liver injury. Proc Natl Acad Sci USA 106: 4402-4407, 2009

138. Mitchell PS, Parkin RK, Kroh EM, Fritz BR, Wyman SK, Pogosova-Agadjanyan EL, Peterson A, Noteboom J, O'Briant $\mathrm{KC}$, Allen A, et al: Circulating microRNAs as stable blood-based markers for cancer detection. Proc Natl Acad Sci USA 105: 10513-10518, 2008

139. Greening DW, Xu R, Ji H, Tauro BJ and Simpson RJ: A protocol for exosome isolation and characterization: Evaluation of ultracentrifugation, density-gradient separation, and immunoaffinity capture methods. Methods Mol Biol 1295: 179-209, 2015. 